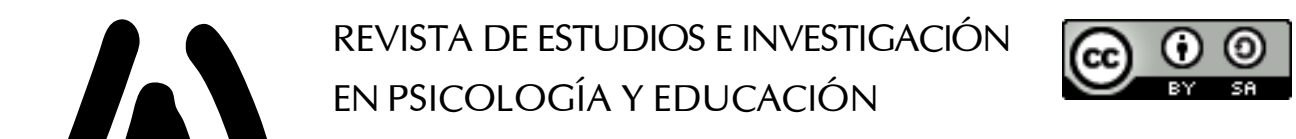 ISSN: 1138-1663; elSSN: 2386-7418 UDC / UMinho 2019, Vol. 6, No. 2, 192-194. \\ DOI: https://doi.org/10.17979/reipe.2019.6.2.5788
}

\section{Reseña del libro: Análisis de contenido soportado por software}

Review of the book: Content analysis supported by software

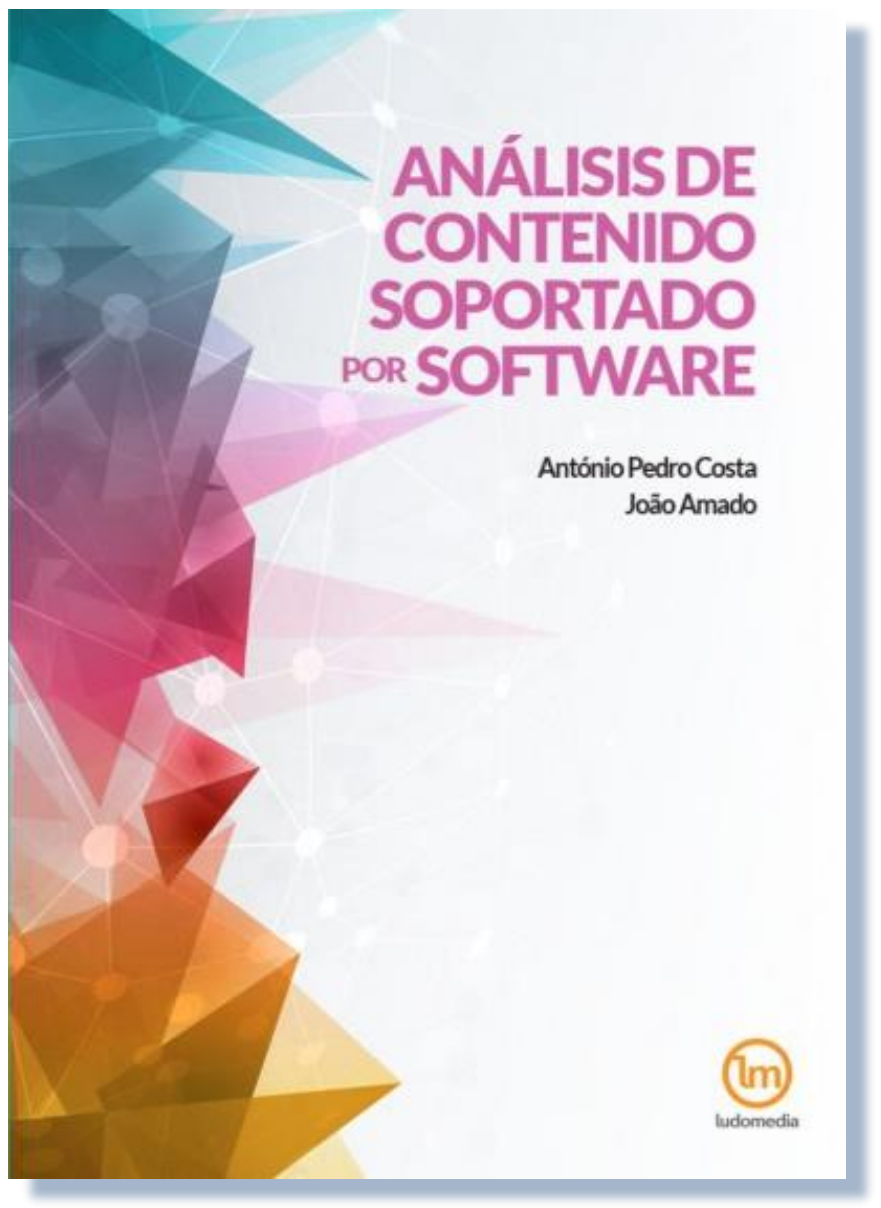

Autores: António Pedro Costa* e João Amado** *Universidade de Aveiro, **Universidade de Coimbra Editorial: Ludomedia

Lugar de edición: Oliveira de Azeméis, Aveiro, Portugal Número de páginas: 60

Año: 2019

ISBN: 978-972-8914-96-7 
El libro objeto de esta reseña está editado por Ludomedia que, en su línea editorial, se ocupa de ofrecer a los profesores e investigadores libros y recursos educativos para diferentes áreas de conocimiento, tales como Salud y Educación. En sus publicaciones se tratan, entre otros, temas relativos a los recursos educativos, la investigación cualitativa y la utilización de software de apoyo al análisis cualitativo. Trata en definitiva de desarrollar contenidos y recursos de excelencia, reflejando lo que de mejor se hace en términos de investigación científica a nivel internacional.

Se trata de un buen ejemplo de esta línea editorial. Aborda el análisis de contenido soportado por software, y pretende ser un manual que trata de sensibilizar y orientar a sus lectores en el uso, como recurso, de herramientas digitales de apoyo al análisis de datos cualitativo.

La valía y experiencia de los autores avala la calidad del libro. En efecto, António Pedro Costa y João Amado, son autores con amplia experiencia como investigadores en investigación cualitativa.

António Pedro Costa es miembro del (CIDTFF) del Departamento de Educación y de Psicología de la Universidad de Aveiro y es colaborador del Laboratorio de Inteligencia Artificial y Ciencia de la Computación (LIACC), de la Facultad de Ingeniería de la Universidad de Oporto. Publicó en coautoría diversos artículos en congresos nacionales e internacionales, artículos en revistas y capítulos de libros. Imparte docencia de unidades curriculares de metodologías de investigación en instituciones de enseñanza superior y es el Coordinador del Congreso Iberoamericano en Investigación y del World Conference on Qualitative Research. Además es uno de los investigadores del software de apoyo al análisis cualitativo webQDA (software utilizado en un ejemplo práctico que se incluye como capítulo en el libro).

Por su parte, João Amado posee una amplísima experiencia como profesor e investigador en las Universidades de Lisboa y Coimbra, es autor y coautor de libros y artículos sobre metodología de la investigación cualitativa, epistemología, pedagogía de la enseñanza superior, etnografía e historia de la infancia.

El libro tiene dos partes diferenciadas. Una primera parte más teórica con dos capítulos. En el primero se trata de situar el análisis de contenido a través de la historia de la técnica y de las distintas definiciones del propio análisis de contenido. En el segundo capítulo se abordan los Programas de Análisis de contenido, con la diversidad de enfoques y potencialidades que tienes estos programas.

En una segunda parte se aborda un ejemplo práctico basado en WebQDA, como ejemplo de software de apoyo a la investigación Cualitativa, tratando de mostrar que las exigencias indispensables para la necesaria calidad de un trabajo bajo enfoque cualitativo, hoy en día, son más fácilmente alcanzables con la ayuda de un software específico como es webQDA.

Se completa el libro con un capítulo de consideraciones finales y los anexos, notas biográficas de los autores y las Referencias.

Se da la circunstancia de que una parte considerable de los investigadores que trabajan con enfoques cualitativos recurren a paquetes de software de análisis cualitativo, en sus trabajos de posgrados y doctorados. Para ellos resulta indispensable disponer de documentación que facilite la aproximación a los programas de investigación cualitativa. El libro trata de cubrir esa necesidad, procurando sensibilizar y orientar a sus lectores para el recurso a herramientas digitales de apoyo al análisis de datos cualitativo.

En cuanto al programa webQDA, sigue el diseño estructural y teórico de otros softwares dedicados al análisis cualitativo, pero con gran simplicidad de utilización y adaptación a diferentes tipos de investigación, con una curva de aprendizaje muy rápida, como he podido comprobar personalmente en mis clases. Por ello es ideal para el tratamiento de datos cualitativos, de forma síncrona o asíncrona, tanto de manera individual como para el trabajo a distancia de equipos de investigación que trabajen de forma colaborativa.

En la segunda parte (Capítulo 3) se explica, apoyándose en un ejemplo, cómo con webQDA se pueden gestionar los procesos de edición, visualización, organización e interconexión de documentos, además de la 
creación de categorías, la codificación y las acciones de control, filtro, búsqueda y análisis de los datos con el objetivo de responder a las preguntas de investigación planteadas en su trabajo.

En resumen, recomiendo la lectura de este libro respaldado, por una parte, en la garantía y solvencia de los autores y, por otra, en que contiene todos los elementos necesarios para que los investigadores se acerquen al trabajo de análisis de contenido con la ayuda de un software y, además, conozcan webQDA, un excelente programa que les puede facilitar el trabajo de la enorme cantidad de datos no numéricos que se recogen en el trabajo de campo en una investigación cualitativa.

Ricardo Luengo (Dorcid.org/0000-0003-4349-8606 Facultad de Educación Universidad de Extremadura Av. de Elvas, s/n, 06006 Badajoz, España rluengo@unex.es

Fecha de recepción: 11 de noviembre de 2019. Fecha de revisión: 11 de noviembre de 2019. Fecha de aceptación: 18 de noviembre de 2019. Fecha de publicación: 1 de diciembre de 2019. 